\title{
Monocyte $1 \alpha$-hydroxylase regulation: induction by inflammatory cytokines and suppression by dexamethasone and uremia toxin
}

\author{
Margaret R. Gyetko,* Chen Hsaing Hsu, ${ }^{\dagger}$ Camille C. Wilkinson,* Sanjeev Patel, ${ }^{\dagger}$ Eric Young ${ }^{\dagger}$ \\ ${ }^{*}$ Division of Pulmonary and Critical Care Medicine and ${ }^{\dagger}$ Division of Nephrology, Department of Internal Medicine, \\ Ann Arbor Department of Veterans Affairs and University of Michigan Medical Centers, Ann Arbor
}

\begin{abstract}
Alveolar macrophages acquire $1 \alpha$-hydroxylase activity in inflammation, and thereby metabolize 25 hydroxyvitamin $D_{3}(25$ D3) to the active metabolite, $1 \alpha, 25$-dihydroxyvitamin $\mathrm{D}_{3}(1,25 \mathrm{D} 3$, calcitriol). Calcitriol is a potent differentiation agent that modulates mononuclear phagocyte activation and effector functions. The mediators that induce macrophage $1 \alpha$-hydroxylase activity are not well delineated. Furthermore, it is unclear whether calcitriol is a product only of terminally differentiated macrophages or whether less mature mononuclear phagocytes can produce it as well. The ability of newly recruited monocytes to produce calcitriol as an autocrine differentiation agent is particularly important in inflammation, as it may substantially expand the functional repertoire of these cells. To assess the effects of cytokines on $1 \alpha$-hydroxylase activity, blood monocytes were cultured in the presence and absence of human recombinant tumor necrosis factor $\alpha$ (TNF- $\alpha)$, interferon- $\gamma$ $($ IFN- $\gamma$ ), and interleukins 1 and 2 and then incubated with 25 D3 substrate. The conditioned media were assayed for calcitriol by high-performance liquid chromatography and competitive receptor binding assay. No detectable calcitriol was produced by unstimulated monocytes. However, all the cytokines markedly increased monocyte calcitriol production (range 133-151 $\mathrm{pg} / \mathrm{mg}$ protein; in all cases $P<.001)$. We then determined whether calcitriol production was suppressed by preincubation with either dexamethasone or the putative uremia toxin guanidinosuccinic acid (GSA). Dexamethasone pretreatment significantly inhibited subsequent cytokine-induced calcitriol production by monocytes, as did GSA (average 69 and $63 \%$ of control, respectively). J. Leukoc. Biol. 53: 17-22; 1993.
\end{abstract}

Key Words: macrophage - inflammation - vitamin $D \cdot$ calcitriol $\cdot$ differentiation

\section{INTRODUCTION}

Disordered vitamin D metabolism is a systemic complication of granulomatous lung diseases. In both sarcoidosis and tuberculosis, hypercalcemia has been shown to be associated with elevated levels of $1 \alpha, 25$-dihydroxyvitamin $D_{3}(1,25 \mathrm{D} 3)$, calcitriol, the most active metabolite of vitamin $D$ [1]. The best recognized pathway for $1 \alpha$-hydroxylation of 25 D3 occurs in the kidney via the microsomal enzyme $1 \alpha$ hydroxylase [1]. However, it has been shown that alveolar macrophages from patients with sarcoidosis spontaneously generate 1,25 D3 in vitro [2]. This is in distinct contrast to alveolar macrophages obtained from normal individuals [3].
The extrarenal production of 1,25 D3 in granulomatous inflammation is of sufficient magnitude to be clinically important, as shown by studies finding elevated blood levels of 1,25 D3 and hypercalcemia in patients with concomitant Mycobacterium tuberculosis infection and end-stage renal disease. In these patients, the renal contribution to serum calcitriol levels is negligible. Appropriate antituberculous therapy returned serum calcitriol values to normal, suggesting that elevated levels of calcitriol were due to the presence of active granulomatous disease [4]. Similar abnormalities in calcium metabolism have been described in anephric sarcoidosis patients [5]. Collectively, these data support the hypothesis that macrophages acquire $1 \alpha$-hydroxylase activity in granulomatous inflammation.

The generation of 1,25 D3 in the inflammatory milieu is likely to have considerable importance beyond effects on calcium metabolism. For example, calcitriol is a potent maturation agent in vitro and is commonly used to differentiate cell lines $[6,7]$. Furthermore, calcitriol induces in vitro differentiation of normal blood monocytes, which, when incubated in the presence of calcitriol, take on the phenotype of alveolar macrophages and, with more prolonged incubation, of multinucleated giant cells [8].

We have previously demonstrated that calcitriol has significant regulatory effects on mononuclear phagocyte proteolytic activity and serves as a priming agent that enhances subsequent responses to inflammatory agonists [9]. Similar priming effects of calcitriol have been described for monocyte/macrophage hydrogen peroxide release $[10,11]$. Calcitriol has also been demonstrated to be a potent modulator of monokine and lymphokine gene expression [12, 13]. Calcitriol receptors have been described in alveolar lymphocytes from patients with granulomatous lung diseases [14]. Collectively, these data strongly support the hypothesis that calcitriol is important in autocrine stimulation and regulation of intercellular crosstalk within inflammatory sites.

The regulatory signals in the inflammatory milieu that trigger the expression of $1 \alpha$-hydroxylase activity by mononuclear phagocytes are not well understood. Furthermore, it is not clear whether $1 \alpha$-hydroxylase activity is acquired during the process of maturation and is therefore expressed only

\footnotetext{
Abbreviations: 1,25 D3, 1 $\alpha, 25$-dihydroxyvitamin $D_{3}$; GSA, guanidinosuccinic acid; HPLC, high-performance liquid chromatography; IFN- $\gamma$, interferon- $\gamma$; IL-1, interleukin-1; PMA, phorbol myristate acetate; TNF- $\alpha$, tumor necrosis factor $\alpha$.

Reprint requests: Margaret R. Gyetko, Pulmonary and Critical Care Medicine Division, University of Michigan Medical Center, 3916 Taubman Center, Ann Arbor, MI 48109-0360.

Received October 5, 1992; accepted March 16, 1993.
} 
by terminally differentiated macrophages, or whether it can be expressed by less mature cells as well. The ability of peripheral blood monocytes to produce calcitriol is of particular importance, as calcitriol could then serve as an autocrine differentiating agent for newly recruited cells in inflammatory foci.

In this study, we sought to determine whether normal human monocytes could be stimulated to produced calcitriol by exposure to the inflammatory cytokines likely to be present in granulomatous inflammation. We then investigated whether the regulation of mononuclear phagocyte $1 \alpha$-hydroxylase activity was similar to or different from the regulation of renal cell $1 \alpha$-hydroxylase activity. We did this through the use of two previously described inhibitors of renal cell $1 \alpha$-hydroxylase, dexamethasone and the uremia toxin guanidinosuccinic acid (GSA) [15, 16]. These inhibitors were especially pertinent to this work because our observations could be relevant to two clinical situations in which host defenses against $M$. tuberculosis are known to be impaired, in patients undergoing treatment with corticosteroids and in those with renal failure [17].

\section{MATERIALS AND METHODS}

\section{Cell culture}

\section{Isolation of monocytes}

Human peripheral blood monocytes were purified from buffy coats provided by the American Red Cross, Detroit, MI. Buffy coats were diluted 1:1 with $5 \mathrm{mM}$ EDTA normal saline and purified by density gradient centrifugation through Lymphoprep (Nycomed AS, Oslo, Norway). After washing with RPMI 1640 (Gibco, Grand Island, NY), cell number was determined by counting in a hemocytometer and viability assessed by trypan blue exclusion. Differential cell counts were determined by examining Giemsa-stained cytocentrifuge samples. The mononuclear cells were resuspended in serum-free medium consisting of RPMI 1640 supplemented with penicillin $(100 \mathrm{U} / \mathrm{ml})$, streptomycin $(100 \mu \mathrm{g} / \mathrm{ml})$, gentamicin $(100 \mu \mathrm{g} / \mathrm{ml})$, L-glutamine $(2 \mathrm{mM})$, and $1 \%(\mathrm{w} / \mathrm{v})$ human serum albumin, and the monocytes were purified by adherence in $35-\mathrm{mm}$ plastic dishes (Corning, Corning, NY) at $2 \times 10^{7}$ cells/well (approximately $8 \times 10^{6}$ monocytes) for $1 \mathrm{~h}$ in humidified air containing $5 \%$ $\mathrm{CO}_{2}$ at $37^{\circ} \mathrm{C}$. Nonadherent cells were removed by washing with RPMI 1640 at $37^{\circ} \mathrm{C}$, and adherent cells were preincubated in serum-free medium in the presence and absence of dexamethasone $\left(10^{-7} \mathrm{M}\right)$ or GSA $(100 \mu \mathrm{g} / \mathrm{ml})$ for $24 \mathrm{~h}$ in humidified air containing $5 \% \mathrm{CO}_{2}$ at $37^{\circ} \mathrm{C}$.

\section{Stimulation of monocytes}

Monocytes were cultured in the presence and absence of tumor necrosis factor $\alpha$ (TNF- $\alpha, 500 \mathrm{U} / \mathrm{ml})$, interferon- $\gamma$ (IFN- $\gamma, 1000 \mathrm{U} / \mathrm{ml}$ ), interleukin-1 (IL-1, $100 \mathrm{U} / \mathrm{ml}$ ), and interleukin-2 (IL-2, $250 \mathrm{U} / \mathrm{ml}$ ) for $24 \mathrm{~h}$ in serum-free medium. All cytokines were human recombinant products supplied by Genzyme, Boston, MA. Culture media and cytokines were found to contain less than 0.02 endotoxin units $/ \mathrm{ml}$, as determined by a Limulus amebocyte lysate assay (Sigma, St Louis, MO).

\section{Measurement of $1 \alpha$-hydroxylase activity}

Calcitriol production by monocytes was measured using established methods [18]. Following a 24-h culture with cytokines, without replacing the medium, $25 \mathrm{D} 3(10 \mu \mathrm{M})$ was added to the cell culture and the monocytes were incubated for $10 \mathrm{~min}$ at $37^{\circ} \mathrm{C}$. The reaction was stopped by placing the culture plates on ice and brief $(<10 \mathrm{~s})$ treatment with an equal volume of ice-cold water. The resulting dilute conditioned medium was rapidly removed and stored at $-20^{\circ} \mathrm{C}$. For measurement of calcitriol, the frozen samples were thawed and vortexed. A small volume $(10 \mu \mathrm{l})$ was removed for protein measurement [19]. To $1 \mathrm{ml}$ of the sample 1000-2000 cpm of $\left[{ }^{3} \mathrm{H}\right]$ calcitriol was added to monitor procedural recovery. One milliliter of acetonitrile was added to deproteinize the specimen. The sample was vortexed for $10 \mathrm{~min}$ and centrifuged at $1000 \mathrm{~g}$ for $10 \mathrm{~min}$. The supernatant was removed, combined with one volume of $0.4 \mathrm{M} \mathrm{K}_{2} \mathrm{HPO}_{4}(\mathrm{pH} 10.4)$, vortexed, and centrifuged at $1000 \mathrm{~g}$ for $10 \mathrm{~min}$. The sample was then applied to a C18 silica preparative column (Waters, Milford, MA). The vitamin D metabolites were eluted with $5 \mathrm{ml}$ of double-distilled water, $5 \mathrm{ml}$ of $70 \%$ methanol, and $5 \mathrm{ml}$ of acetonitrile. The acetonitrile fraction containing the hydroxylated vitamin D metabolites was collected, dried, and reconstituted in $500 \mu \mathrm{l}$ of HPLC solvent consisting of $88 \%$ hexane, $10 \%$ isopropanol, and $2 \%$ methanol (solvent system A). The sample was then applied to a 5- $\mu \mathrm{m}$ silica analytical column (Alltech 605 SI, Deerfield, IL) using a Waters HPLC system at a flow rate of $4 \mathrm{ml} / \mathrm{min}$ with the mobile phase described above. The fraction containing calcitriol, as calibrated by cold calcitriol standard, was collected.

The HPLC-purified sample was dried and reconstituted in $100 \mu$ l of ethanol. A portion of the sample $(25 \mu \mathrm{l})$ was counted to estimate procedural losses. Calcitriol recovery averaged $50 \%$. The remainder (25- $\mu 1$ samples in duplicate) was used for quantitative measurement of calcitriol using a calcitriol receptor assay according to the method of Reinhardt and Hollis [20, 21]. In other cell systems, this method has been shown to separate calcitriol from other vitamin D metabolites including 19-nor, 10-keto-25 $(\mathrm{OH}) \mathrm{D}_{3}$ (19-nor metabolite) [22-24]. Briefly, the samples were combined with calf thymus calcitriol receptor and incubated in a shaking water bath at $25^{\circ} \mathrm{C}$. Approximately $5000 \mathrm{cpm}$ of $\left[{ }^{3} \mathrm{H}\right]$ calcitriol was added. After appropriate incubation, the samples were iced and dextran-coated charcoal was added to remove unbound activity. The samples were vortexed and iced for $\mathbf{1 5} \mathrm{min}$, the charcoal pelleted by centrifugation, and the supernatants decanted into scintillation vials for counting. For each assay, we generated a standard curve using known amounts of calcitriol and determined nonspecific binding by adding a 100-fold excess of cold calcitriol (specific binding = total - nonspecific binding). The calcitriol content of the samples was determined from the standard curve. The intraassay coefficients of variation are $5.4 \%$ for low control $(20 \mathrm{pg} / \mathrm{ml})$ and $4.7 \%$ for high control $(100 \mathrm{pg} / \mathrm{ml})$, with a detection limit of $5 \mathrm{pg} / \mathrm{ml}$. The interassay coefficients of variation are $7 \%$ for low control and $4.1 \%$ for high control.

To further exclude any potential contribution of the 19-nor metabolite, the described dilute conditioned medium samples were purified by a second HPLC solvent system known to separate calcitriol completely from the 19-nor metabolite, in addition to purification by solvent system $A$ (samples were divided and run in parallel on the two systems) [23]. The second solvent system (B) consisted of $93 \%$ dichloromethane and $7 \%$ isopropanol. Calcitriol from the appropriate fractions was then quantitated by calcitriol receptor binding as described earlier. The amount of calcitriol detected was compared for the two solvent systems for each sample.

\section{Statistics}

For all experiments, comparisons between groups were performed using an unpaired Student's $t$-test [25]. All data are 
expressed as mean \pm SEM. Number $(n)=$ number of donors, each donor contributing monocytes for one experiment.

\section{RESULTS}

\section{Cell culture}

Buffy coat mononuclear cells consisted of approximately $40 \%$ monocytes, and adherent cell preparations were routinely $>94 \%$ monocytes and $>95 \%$ viable by trypan blue exclusion. Cells, with or without dexamethasone or GSA pretreatment, in the presence or absence of cytokines, were routinely $>90 \%$ viable at the conclusion of the incubation period. Cell viability was again assessed after the $1 \alpha$ hydroxylation reaction was stopped, immediately after removal of diluted conditioned medium, and was essentially unchanged.

\section{Effects of cytokines of production of 1,25 D3 by monocytes}

After incubation in the presence and absence of inflammatory cytokines, $25 \mathrm{D} 3$ substrate was added to the monocyte cultures. After $10 \mathrm{~min}$ the reaction was stopped and diluted medium was removed and assayed for calcitriol content as detailed in Materials and Methods. No calcitriol was detected in medium alone or when ethanol (25 D3 diluent) alone was added to cells (data not shown). No detectable calcitriol was produced by monocytes under control conditions. All the cytokines tested significantly increased production of calcitriol by monocytes. IFN increased production of calcitriol to $133.16 \pm 8.62 \mathrm{pg} / \mathrm{mg}$ protein, TNF to $143.43 \pm$ 5.69 , IL-1 to $150.61 \pm 5.52$, and IL-2 to $144.01 \pm 8.57$ (in all cases $P<.001, n=8$ donors; Fig. 1). The data, expressed in terms of total calcitriol per culture well, are control, no detectable calcitriol; IFN, $45.09 \pm 3.68 \mathrm{pg} /$ well; TNF, $46.98 \pm$ 2.98; IL-1, $53.93 \pm 4.78 ;$ IL-2, $47.43 \pm 5.58$ (in all cases $P<.001$; range $112-135 \mathrm{pM})$. There were no statistically significant differences among the cytokines in the level of calcitriol synthesis they induced. Lysing the monocytes in con-

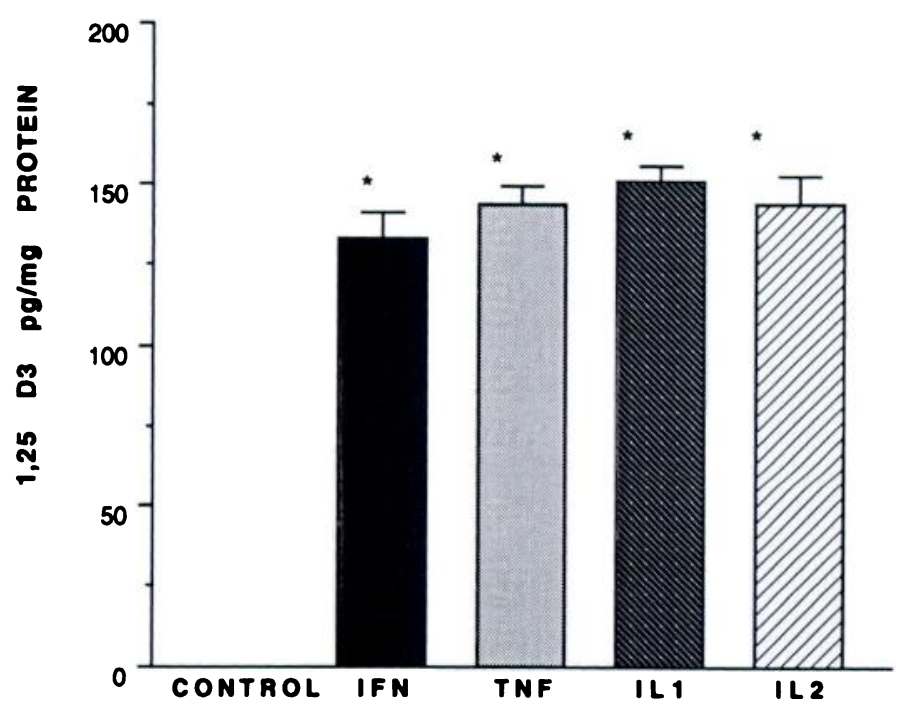

Fig. 1. Calcitriol production by peripheral blood monocytes. Incubation with human recombinant IFN $(1000 \mathrm{U} / \mathrm{ml})$, TNF $(500 \mathrm{U} / \mathrm{ml})$, IL-1 $(100 \mathrm{U} / \mathrm{ml})$, or IL-2 $(250 \mathrm{U} / \mathrm{ml})$ induced monocyte $1 \alpha$-hydroxylase and conversion of 25 D3 to 1,25 D3. Calcitriol levels are measured in conditioned medium and expressed in $\mathrm{pg} / \mathrm{mg}$ protein \pm SEM. ${ }^{*} P<.001 ; n=8$ donors.
TABLE 1. Exclusion of 19-nor Metabolite by Comparison of Alternative HPLC Solvent Systems ${ }^{a}$

\begin{tabular}{ccc}
\hline & \multicolumn{2}{c}{ Calcitriol levels $(\mathrm{pg} / \mathrm{mg}$ protein) } \\
\cline { 2 - 3 } Sample number & Solvent system A & Solvent system B \\
\hline 2 & 93.1 & 95.9 \\
8 & 60.5 & 64.6 \\
10 & 86.2 & 90.6 \\
13 & 123.7 & 125.4 \\
15 & 73.0 & 73.9 \\
18 & 149.7 & 147.1 \\
\hline
\end{tabular}

${ }^{a}$ Samples were divided and purified in parallel by two HPLC solvent systems; calcitriol was then quantitated by receptor binding as detailed in methods. Solvent system A consists of $88 \%$ hexane, $10 \%$ isopropanol, and $2 \%$ methanol; solvent system B consists of $93 \%$ dichloromethane and $7 \%$ isopropanol (widely separates calcitriol from the 19-nor metabolite).

ditioned medium prior to assay increased the average protein content from $302.8 \pm 3.3$ to $636.8 \pm 7.8 \mu \mathrm{g} / \mathrm{ml}$ conditioned medium but did not significantly alter the amount of calcitriol per milligram of protein. We conclude from these data that unstimulated monocytes do not express $1 \alpha$-hydroxylase activity but respond to inflammatory cytokines by upregulating $1 \alpha$-hydroxylase and synthesizing calcitriol from exogenous 25 D3 substrate. Furthermore, the calcitriol produced is released in significant amounts into the extracellular environment, where it is available for paracrine interactions.

\section{Documentation of authentic calcitriol and exclusion of the 19-nor, 10-keto-25 (OH) D3 metabolite}

Investigators have reported that phagocytic cells have the capacity to convert $25 \mathrm{D} 3$ to 19 -nor, 10-keto-25 (OH) D3 (19-nor metabolite), a minor metabolite that comigrates with authentic calcitriol on some HPLC systems $[23,26]$. Although contribution of the 19-nor metabolite should be essentially eliminated in our system by the receptor binding assay (calcitriol has a binding affinity for the calcitriol receptor approximately 600 times that of the 19-nor metabolite), we sought to determine definitively whether the 19-nor metabolite could be contributing to our calcitriol measurement [27]. We therefore divided aliquots of the previously described dilute monocyte-conditioned medium into two portions and assayed them in parallel on the two HPLC solvent systems detailed in Materials and Methods. Solvent system B was specifically chosen because it completely separates authentic calcitriol from the 19-nor metabolite [23]. The appropriate HPLC fractions were collected and calcitriol was quantitated by receptor binding assay. If the 19-nor metabolite comigrated with authentic calcitriol with solvent system $A$ and contributed to the receptor binding assay measurement of calcitriol, less calcitriol would be measured by receptor binding assay when the sample was purified by HPLC system B (which effectively removes the 19-nor metabolite from the calcitriol fraction). In each case, the amount of calcitriol quantitated by receptor binding was within assay variability when purification by HPLC solvent system A was compared with purification by HPLC solvent system B (Table 1). Therefore, we can conclude that the 19-nor metabolite is not significant in our system. We were not surprised by this finding because the 19 -nor metabolite is an oxidative product usually produced after prolonged culture with 25 D3 substrate; our culture conditions limited exposure to the substrate to only $10 \mathrm{~min}$. 


\section{Effects of dexamethasone preincubation on monocyte} calcitriol production

Whereas all the inflammatory cytokines tested induced similar calcitriol production, we sought to determine whether cytokine up-regulation of $1 \alpha$-hydroxylase activity could be suppressed and whether cytokines varied in their ability to overcome suppressive effects. We chose dexamethasone as a suppressive agent for several reasons. Glucocorticoids are widely used clinically for the treatment of sarcoidosis; hypercalcemia is considered a traditional indication for the initiation of such therapy [28]. It has been shown that in hypercalcemic sarcoidosis patients, circulating levels of calcitriol are elevated, and after the initiation of glucocorticoid therapy calcitriol levels fall rapidly, followed by a decrease in serum calcium levels [29]. This suggests that glucocorticoids suppress the $1 \alpha$-hydroxylase activity of granuloma-associated macrophages. Furthermore, dexamethasone is a known suppressor of $1 \alpha$-hydroxylase activity. Dexamethasone, in concentrations similar to those reported here, has been shown to suppress calcitriol production by kidney cells in vitro to approximately $60 \%$ of control levels [15].

Following preincubation with dexamethasone $\left(10^{-7} \mathrm{M}\right)$ unstimulated monocytes produced no detectable calcitriol. Dexamethasone pretreatment significantly inhibited subsequent cytokine-induced calcitriol production by monocytes. Dexamethasone inhibited the response to IFN to $66 \%$ of the level seen without dexamethasone pretreatment (IFN alone compared to dexamethasone followed by IFN, $P<.001)$. Likewise, the TNF response was inhibited to $71 \%$ $(P<.001)$, the IL-1 response to $62 \%(P<.001)$, and the IL-2 response to $77 \%(P<.015, n=10$ donors; Fig. 2). We can conclude, therefore, that dexamethasone suppresses cytokine-induced calcitriol production by monocytes. Furthermore, it appears that the effect of dexamethasone suppression is similar among the cytokines tested. This level of suppression is also similar to that seen in kidney cell cultures in vitro [15].

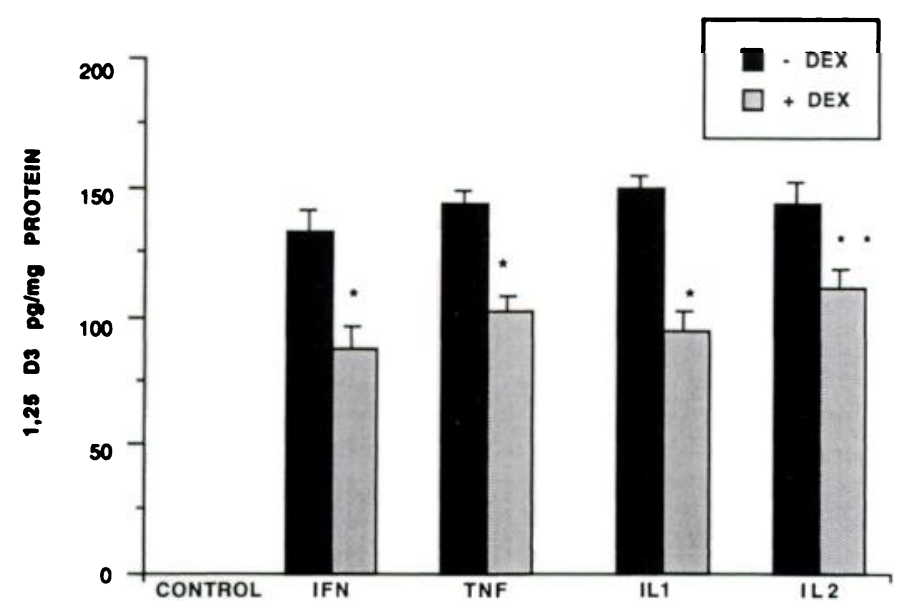

Fig. 2. Dexamethasone suppression of cytokine-induced calcitriol production by peripheral blood monocytes. Preincubation with dexamethasone $\left(10^{-7} \mathrm{M}\right)$ suppresses subsequent cytokine-induced calcitriol production. Cytokine doses used were IFN $(1000 \mathrm{U} / \mathrm{ml})$, TNF $(500 \mathrm{U} / \mathrm{ml})$, IL-1 $(100 \mathrm{U} / \mathrm{ml})$, or IL-2 $(250 \mathrm{U} / \mathrm{ml})$. Calcitriol levels are measured in conditioned medium and expressed in $\mathrm{pg} / \mathrm{mg}$ protein \pm SEM. Cytokine alone compared to dexamethasone incubation followed by cytokine stimulation; $\bullet P<.001, \cdots P<.015 ; n=10$ donors.

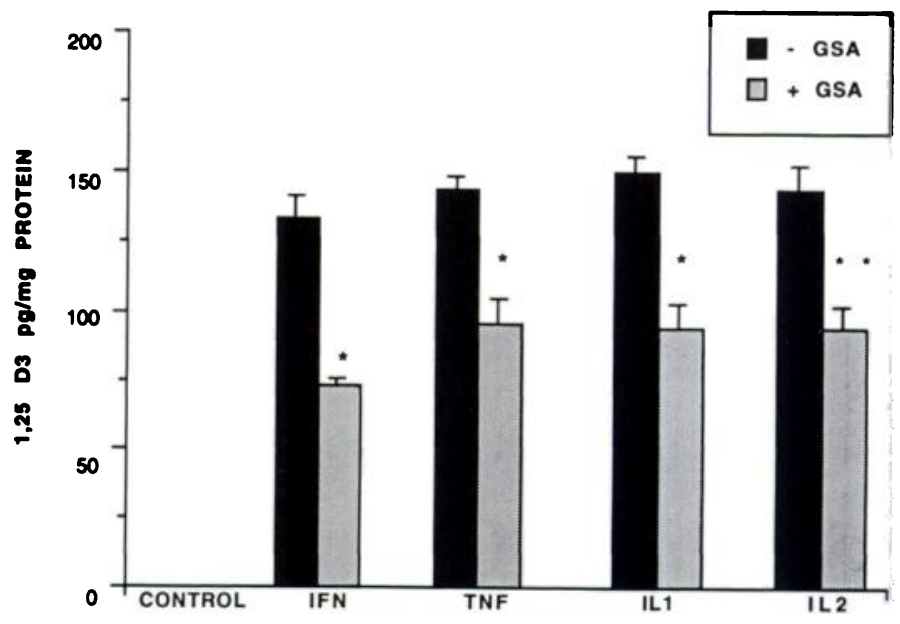

Fig. 3. GSA suppression of cytokine-induced calcitriol production by peripheral blood monocytes. Preincubation with GSA $(100 \mu \mathrm{g} / \mathrm{ml})$ suppresses subsequent cytokine-induced calcitriol production. Cytokine doses used were IFN $(1000 \mathrm{U} / \mathrm{ml})$, TNF $(500 \mathrm{U} / \mathrm{ml})$, IL-1 $(100 \mathrm{U} / \mathrm{ml})$, or IL-2 $(250 \mathrm{U} / \mathrm{ml})$. Calcitriol levels are measured in conditioned medium and expressed in $\mathrm{pg} / \mathrm{mg}$ protein \pm SEM. Cytokine alone compared to GSA incubation followed by cytokine stimulation; ${ }^{*} P<.001,{ }^{* *} P<.005 ; n=4$ donors.

\section{Effects of GSA preincubation on monocyte calcitriol production}

To further delineate the regulation of calcitriol production by monocytes, we next sought to determine whether the uremia toxin GSA, a potent inhibitor of renal tubule cell $1 \alpha$ hydroxylase activity, would also inhibit monocyte calcitriol production [16]. The concentration of GSA used for these studies, $100 \mu \mathrm{g} / \mathrm{ml}$, exceeds the average concentration of GSA in the sera of hemodialysis patients in whom GSA is thought to be the major inhibitor of renal tubule $1 \alpha$ hydroxylase activity [30]. GSA pretreatment significantly inhibited subsequent cytokine-induced calcitriol production by monocytes. GSA inhibited the response to IFN to $55 \%$ of the level seen without GSA pretreatment (IFN alone compared to GSA followed by IFN, $P<.001)$. Similarly, the TNF response was inhibited to $66 \%(P<.001)$, the IL-1 response to $63 \%(P<.001)$, and the IL-2 response to $66 \%(P<.005$, $n=4$ donors; Fig. 3). We conclude, therefore, that GSA suppresses cytokine-induced monocyte $1 \alpha$-hydroxylase activity. By comparison, we performed similar experiments using confluent cultures of murine kidney cells. In these experiments, $40 \mu \mathrm{g} / \mathrm{ml} \mathrm{GSA}$ suppressed calcitriol production to approximately $50 \%$ of control levels (data not shown).

\section{DISCUSSION}

Peripheral blood monocytes are recruited to sites of inflammation, where they differentiate and become activated [31, 32]. Despite extensive investigation, the precise signals that modulate these changes remain unclear [33]. We propose that the elaboration of calcitriol is an autocrine mechanism by which mononuclear phagocytes regulate differentiation and activation in response to inflammatory mediators. If this is true, the expression of $1 \alpha$-hydroxylase activity and the production of calcitriol would not be regulated solely by terminally differentiated macrophages, but these would be expressed by newly recruited monocytes as they are exposed to the inflammatory milieu. It is further likely that the cyto- 
kines generated in granulomatous inflammation would play a key regulatory role in initiating this activity.

The results of the current study support this paradigm. Monocytes did not produce any detectable calcitriol under unstimulated conditions. However, when they were stimulated with TNF, IFN, IL-1, or IL-2, significant amounts of calcitriol were produced rapidly from exogenously added 25 D3 substrate. The relatively high concentration of calcitriol in the conditioned medium of stimulated monocytes argues against a sequestered intracellular pool of this metabolite and instead places it extracellularly, in a propitious site for its paracrine effects on neighboring $T$ cells as well as on monocyte/macrophages.

Prior work has demonstrated that pulmonary macrophages from patients with granulomatous inflammation express $1 \alpha$-hydroxylase activity [2, 3]. Other investigators have extended this observation by showing that normal alveolar and culture-derived macrophages can produce calcitriol under some conditions of stimulation [34-37]. The present study, together with these observations, supports the hypothesis that $1 \alpha$-hydroxylase activity is a monocyte/macrophage effector function that can be modulated by inflammatory mediators in vitro and is active during granulomatous inflammation in vivo.

Much is known about the effects of calcitriol on inflammatory cells. Calcitriol is a potent differentiating agent $[1,38]$. This has been well demonstrated in cell lines, most notably in U937 cells and HL60 cells, as well as other cells of mononuclear phagocyte lineage [39-41]. For example, incubation of U937 cells with calcitriol $\left(10^{-11}-10^{-10} \mathrm{M}\right)$ induces an increase in Fc receptors, OKM1 binding, $\alpha$-naphthyl esterase staining, phagocytosis, and antibody-dependent cellular cytotoxicity, while decreasing proliferation; these changes are typical of a more mature cell [42, 43]. Calcitriol also effects differentiation of normal cells of mononuclear phagocyte lineage. Incubation of normal human monocytes with calcitriol $\left(10^{-8} \mathrm{M}\right)$ in the absence of serum promotes differentiation to the macrophage phenotype, as assessed by release of interleukin-6 and TNF as well as secretion of lysozyme and fibronectin [38]. Prolonged incubation of monocytes in the presence of calcitriol $\left(10^{-8} \mathrm{M}\right)$ and $10 \%$ serum gives rise to large, epithelioid, multinucleated giant cells with long survival times ( $>3$ months) that are similar to cells seen in granulomata in vivo [8]. These observations indicate that calcitriol affects the entire spectrum of mononuclear phagocyte differentiation, from monocyte to macrophage to the classic phenotype of granulomatous inflammation, the multinucleated giant cell. The current study highlights the importance of these mechanisms in the context of inflammation by demonstrating that undifferentiated, cytokine-stimulated monocytes produce calcitriol, thereby directing differentiation in an autocrine fashion.

Calcitriol also has immune modulating effects on mononuclear phagocytes. Monocytes treated with calcitriol release increase amounts of prostaglandin $E_{2}, I L-1$, and hydrogen peroxide $[10,44]$. Of interest is the priming effect of calcitriol. Preincubation with calcitriol markedly enhances lipopolysaccharide-induced mononuclear phagocyte IL-1 and TNF production as well as phorbol myristate acetate (PMA)-induced hydrogen peroxide production [11, 13, 45]. This implies that, in addition to its direct effects, calcitriol serves to sensitize mononuclear phagocytes to subsequent inflammatory signals. Along these lines, we have reported a role for calcitriol in the regulation of mononuclear phagocyte proteolytic activity. Incubation with calcitriol alone enhances mononuclear phagocyte plasminogen activator activity. However, preincubation with calcitriol markedly enhances
PMA-induced expression of plasminogen activator inhibitor activity [46]. Thus, the priming effect of calcitriol may expand significantly the repertoire of cellular responses to inflammatory signaling. In contrast to the enhancement of mononuclear phagocyte function seen after the addition of calcitriol, vitamin D-deficient animals have markedly impaired macrophage function, including defective antitumor activities, decreased migratory responses to inflammatory stimuli, and decreased phagocytosis $[47,48]$.

The generation of calcitriol at inflammatory sites may be of particular benefit in the defense against tuberculosis. In vitro studies demonstrated that calcitriol substantially increased intracellular killing of $M$. tuberculosis by macrophages and is synergistic with pyrazinamide $[44,49,50]$. It is intriguing that several subpopulations recognized to be at increased risk for the development of clinical tuberculosis (patients with renal failure, the elderly, the malnourished, etc.) are also known to have altered vitamin $\mathrm{D}$ metabolism or frank vitamin D deficiency $[17,51]$. In support of this connection, a study of elderly vitamin D-deficient patients demonstrated a lack of hypersensitivity to purified protein derivative that was reconstituted by vitamin $\mathrm{D}$ repletion [52].

To further investigate mononuclear phagocyte $1 \alpha$-hydroxylase regulation, we preincubated the cells in either dexamethasone or GSA before cytokine stimulation. These two agents were chosen because of their well-documented inhibitory effects on renal cell $1 \alpha$-hydroxylase and because they may be key factors in two groups of patients who have increased susceptibility to tuberculosis - renal failure patients and those receiving high doses of corticosteroids [17]. We saw significant inhibition of cytokine-induced calcitriol production when monocytes were preincubated with either dexamethasone or GSA. Therefore, qualitatively, regulation of mononuclear phagocyte $1 \alpha$-hydroxylase activity is similar to that seen by renal cells. Dexamethasone is similar in the magnitude of its suppressive effects on either renal cell or stimulated monocyte calcitriol production [15]. GSA may be a more potent inhibitor of renal cell calcitriol production (50\% inhibition) than monocyte calcitriol production (approximately $63 \%$ of control). Therefore, it appears that the regulation of monocyte $1 \alpha$-hydroxylase activity may differ in some respects from renal cell regulation, and further study is needed.

In summary, we have demonstrated that peripheral blood monocytes acquire $1 \alpha$-hydroxylase activity and produce calcitriol on exposure to inflammatory cytokines. Furthermore, this activity can be suppressed by corticosteroids or uremia toxin. The production of calcitriol, therefore, is a mononuclear phagocyte function that is mediated by signals present in the inflammatory milieu. Cytokine-induced $1 \alpha$ hydroxylase activity is subject to modification by therapeutic agents (corticosteroids) and underlying metabolic conditions (uremia). It is likely that the elaboration of calcitriol by newly recruited monocytes contributes significantly to the differentiation and activation of these cells in sites of granulomatous inflammation.

\section{ACKNOWLEDGMENT}

This work was supported by a Department of Veterans Affairs Merit Review Research Grant.

\section{REFERENCES}

1. Reichel, H., Koeffler, H., Norman, A. (1989) The role of the vitamin D endocrine system in health and disease. N. Engl. J. Med. 320, 980-991.

2. Adams, J., Sharma, O., Gacad, M., Singer, F. (1983) Metabolism of 
25-hydroxyvitamin $\mathrm{D}_{3}$ by cultured pulmonary alveolar macrophages in sarcoidosis. J. Clin. Invest. 72, 1856-1860.

3. Reichel, H., Koeffler, H., Barbers, R., Norman, A. (1987) Regulation of 1,25-dihydroxyvitamin $D_{3}$ production by cultured alveolar macrophages from normal human donors and from patients with pulmonary sarcoidosis. J. Clin. Endocrinol. Metab. 65, 1201-1209.

4. Gkonos, P., London, R., Hendler, E. (1984) Hypercalcemia and elevated 1,25-dihydroxyvitamin $D$ levels in a patient with end-stage renal disease and tuberculosis. $N$. Engl. J. Med. 311, 1683-1685.

5. Barbour, G., Coburn, J., Slatopolsky, E., Norman, A., Horst, R. (1981) Hypercalcemia in an anephric patient with sarcoidosis: evidence for extra-renal generation of 1,25-dihydroxyvitamin D. N. Engl. J. Med. $305,440-443$.

6. Gray, T., Cohen, M. (1985) Vitamin D, phagocyte differentiation and immune function. Surv. Immunol. Res. 4, 200-212.

7. Teitelbaum, S., Hruska, K. (1990) 1,25-Dihydroxycholecalciferol and macrophage differentiation with aging. Exp. Gerontol. 25, 233-238.

8. Ohta, M., Okabe, T., Ozawa, K., Urabe, A., Takaku, F. (1986) In vitro formation of macrophage-epithelioid cells and multinucleated giant cells by $1 \alpha, 25$-dihydroxyvitamin $\mathrm{D}_{3}$ from human circulating monocytes. Ann. N.Y. Acad. Sci. 465, 211-220.

9. Gyetko, M., Webb, A., Sitrin, R. (1988) Modulation of urokinase-type plasminogen activator and plasminogen activator inhibitor-2 expression by U937 mononuclear phagocytes. $J$. Immunol. 141, 2693-2698.

10. Cohen, M., Mesler, D., Snipes, R., Gray, T. (1986) 1,25 Dihydroxyvitamin $\mathrm{D}_{3}$ activates secretion of hydrogen peroxide by human monocytes. J. Immunol. 136, 1049-1053.

11. Gluck, W., Weinberg, J. (1987) $1 \alpha, 25$-Dihydroxyvitamin $D_{3}$ and mononuclear phagocytes: enhancement of mouse macrophage and human monocyte hydrogen peroxide production without alteration of tumor cytolysis. J. Leukoc. Biol. 42, 498-503.

12. Bhalla, A., Paavonen, T., Williams, M., Delves, P., Lydyard, D. (1991) Regulation of interleukin-1 and tumour necrosis factor gene expression in myelomonocytic cell lines by 1,25 -dihydroxyvitamin $\mathrm{D}_{3} . \mathrm{J}$. Immunol. 72, 61-64.

13. Fagan, D., Prehn, J., Adams, J., Jordan, S. (1991) The human myelomonocytic cell line U937 as a model for studying alterations in steroidinduced monokine gene expression: marked enhancement of lipopolysaccharide-stimulated interleukin-1B messenger RNA levels by 1,25-dihydroxyvitamin $\mathrm{D}_{3}$. Mol. Endocrinol. 5, 179-186.

14. Biyoudi-Vouenze, R., Cadranel, J., Valeyre, D., Milleron, B., Hance, A., Soler, P. (1991) Expression of 1,25(OH $)_{2} D_{3}$ receptors on alveolar lymphocytes from patients with pulmonary granulomatous diseases. Am. Rev. Respir. Dis. 143, 1376-1380.

15. Henry, H. (1986) Effect of dexamethasone on 25-hydroxyvitamin $D_{3}$ metabolism by chick kidney cell cultures. Endocrinology 118, 1134-1186.

16. Patel, S., Hsu, C. (1990) Effect of polyamines, methylguanidine, and guanidinosuccinic acid on calcitriol synthesis. J. Lab. Clin. Med. 115, 69-73.

17. Bloch, A., Rieder, H., Kelly, G., Cauthen, G., Hayden, C., Snider, D. (1989) The epidemiology of tuberculosis in the United States. Implications for diagnosis and treatment. Clin. Chest Med. 10, 297-313.

18. Langman, C., Favus, M., Bushinsky, D., Coe, F. (1985) Effects of dietary calcium restriction on 1,25-dihydroxyvitamin $D_{3}$ net synthesis by rat prominal tubules. J. Lab. Clin. Med. 106, 286-292.

19. Lowry, O.H., Rosebrough, N.J., Karr, A.L., Randall, R.J. (1951) Protein measurement with Folin phenol reagent. J. Biol. Chem. 193, 265-274.

20. Reinhardt, T., Hollis, B. (1986) 1,25-Dihydroxyvitamin D microassay employing radioreceptor techniques. Methods Enzymol. 123, 176-185.

21. Hollis, B.W. (1986) Assay of circulating 1,25-dihydroxyvitamin D involving a novel single-cartridge extraction and purification procedure. Clin. Chem. 32, 2060-2063.

22. Patel, S., Simpson, R., Hsu, C. (1989) Effect of vitamin D metabolites on calcitriol metabolism in experimental renal failure. Kidney Int. 36, 234-239.

23. Langman, C., Bushinsky, D., Favus, M., Coe, F. (1986) Ca and P regulation of $1,25(\mathrm{OH})_{2} \mathrm{D}_{3}$ synthesis by vitamin $\mathrm{D}$-replete rat tubules during acidosis. Am. J. Physiol. 251, F911-F918.

24. Lobaugh, B., Almond, J., Drezner, M. (1986) Measurement of 25-hydroxyvitamin D 1 alpha hydroxylase activity in mammalian kidney. Methods Enzymol. 123, 159-167.

25. Zar, J.H. (1984) Biastatistical Analysis. Prentice-Hall, Englewood Cliffs, NJ, 121-129.

26. Gray, T., Millington, D., Maltby, D., Williams, M., Cohen, M., Dodd, R. (1985) Phagocytic cells synthesize 19-nor-10-keto-hydroxyvitamin $D_{3}$, a metabolite that may induce differentiation of the human monoblastic cell line U937. Proc. Natl. Acad. Sci. USA 82, 8218-8221.
27. Gray, T.K., Kleckner, N.W., Malloy, P.J., Feldman, D., Sivam, G., Dodd, R.C., Cohen, M.S. (1987) Biological activity of 19-nor, 10-keto, 25-hydroxyvitamin $D_{3}$. J. Bone Miner. Res. 2, 413-419.

28. Mitchell, D., Scadding, J. (1974) Sarcoidosis. Am. Rev. Respir. Dis. 110, 774-802.

29. Sandler, L., Winearls, C., Fraher, L., Clemens, T., Smith, R., ORiordan, J. (1984) Studies of the hypercalcaemia of sarcoidosis: effect of steroids and exogenous vitamin $D_{3}$ on the circulating concentrations of 1,25-dihydroxyvitamin $\mathrm{D}_{3}$. Q. J. Med. 53, 165-180.

30. Stein, I.M., Buron, B.D., Kornhausser, R.S. (1969) Guanidinosuccinic acid in renal failure, experimental azotemia and inborn errors of the urea cycle. N. Engl. J. Med. 280, 926-930.

31. Adams, D., Hamilton, T. (1989) The activated macrophage and granulomatous inflammation. Curr. Top. Pathol. 79, 151-167.

32. Adams, D., Hamilton, T. (1984) The cell biology of macrophage activation. Annu. Rev. Immunol. 2, 283-318.

33. Adams, D., Koerner, T. (1988) Gene regulation in macrophage development and activation. In The Year in Immunology 1988 (J. Cruse and R. L. Jr., eds), Karger, Basel, 4, 159-180.

34. Reichel, H., Koeffler, H., Bishop, J., Norman, A. (1987) 25- Hydroxyvitamin $\mathrm{D}_{3}$ metabolism by lipopolysaccharide-stimulated normal human macrophages. J. Clin. Endocrinol. Metab. 64, 1-9.

35. Reichel, H., Koeffler, H., Norman, A. (1987) Synthesis in vitro of 1,25dihydroxyvitamin $D_{3}$ and 24,25-dihydroxyvitamin $D_{3}$ by interferon$\gamma$-stimulated normal human bone marrow and alveolar macrophages. J. Biol. Chem. 262, 10931-10937.

36. Koeffler, H., Reichel, H., Bishop, J., Norman, A. (1985) $\gamma$-Interferon stimulates production of 1,25 -dihydroxyvitamin $\mathrm{D}_{3}$ by normal human macrophages. Biochem. Biophys. Res. Commun. 127, 596-603.

37. Pryke, A., Duggan, C., White, C., Posen, S., Mason, R. (1990) Tumor necrosis factor-alpha induces vitamin D-1-hydroxylase activity in normal human alveolar macrophages. J. Cell. Physiol. 142, 652-656.

38. Kreutz, M., Andreesen, R. (1990) Induction of human monocyte to macrophage maturation in vitro by 1,25 -dihydroxyvitamin $\mathrm{D}_{3}$. Blood 76, 2457-2461

39. Abe, E. (1981) Differentiation of mouse myeloid leukemia cells induced by $1 \alpha, 25$-dihydroxyvitamin $\mathrm{D}_{3}$. Proc. Natl. Acad. Sci. USA 78, 4990-4994.

40. Tanaka, H., Abe, E., Miyaura, C., Kuribayashi, T., Konno, K. Nishii, Y., Suda, T. (1982) 1 $\alpha, 25$-Dihydroxycholecalciferol and a human myeloid leukaemia cell line (HL-60). Biochem. J. 204, 713-719.

41. Munker, R., Norman, A., Koeffler, H. (1986) Vitamin D compounds: effect on clonal proliferation and differentiation of human myeloid cells. J. Clin. Invest. 78, 424-430.

42. Amento, E., Bhalla, A., Kurnick, J., Kradin, R., Clemens, T. Holick, S., Holick, M., Krane, S. (1984) 1 $\alpha, 25$-Dihydroxyvitamin $\mathrm{D}_{3}$ induces maturation of the human monocyte cell line U937, and, in association with a factor from human $\mathrm{T}$ lymphocytes, augments production of the monokine, mononuclear cell factor. J. Clin. Invest. 73, 731-739.

43. Rigby, W., Shen, L., Ball, E.D., Guyre, M., Fanger, M.W. (1984) Differentiation of a human monocytic cell line by 1,25-dihydroxyvitamin $\mathrm{D}_{3}$ (calcitriol): a morphologic, phenotypic and functional analysis. Blood 64, 1110.

44. Rigby, W. (1988) The immunobiology of vitamin D. Immunol. Today 9, 54-58.

45. Rook, G., Taverne, J., Leveton, C., Steele, J. (1987) The role of gamma-interferon, vitamin $D_{3}$ metabolites and tumour necrosis factor in the pathogenesis of tuberculosis. Immunology 62, 229-234.

46. Gyetko, M., Sitrin, R. (1990) Cytokine regulation of mononuclear phagocyte plasminogen activator activity. Clin. Res. 38, A439.

47. Bar-Shavit, Z. (1981) 1,25-Dihydroxyvitamin $D_{3}$ and the regulation of macrophage function. Calcif. Tissue Int. 33, 673-676.

48. Gavison, R., Bar-Shavit, Z. (1989) Impaired macrophage activation in vitamin $D_{3}$ deficiency: differential in vitro effects of 1,25-dihydroxyvitamin $D_{3}$ on mouse peritoneal macrophage functions. J. Immunol. 143, 3686-3690.

49. Crowle, A., Salfinger, M., May, M. (1989) 1,25(OH $)_{2}$-vitamin $D_{3}$ synergizes with pyrazinamide to kill tubercle bacilli in cultured human macrophages. Am. Rev. Respir. Dis. 139, 549-552.

50. Crowle, A., Ross, E. (1990) Comparative abilities of various metabolites of vitamin $\mathrm{D}$ to protect cultured human macrophages against tubercle bacilli. J. Leukoc. Biol. 47, 545-550.

51. Crowle, A., Elkins, N. (1990) Relative permissiveness of macrophages from black and white people for virulent tubercle bacilli. Infect. Immun. 58, 632-638.

52. Toss, G., Symreng, T. (1982) Delayed hypersensitivity response and vitamin D deficiency. Int. J. Vitam. Nutr. Res. 53, 27-31. 